\title{
Cost impact of a non-invasive, portable device for patient self-administration of chronic migraine in a UK National Health Service setting
}

\author{
B. Brüggenjürgen ${ }^{1,2^{*}} \mathbb{D}$, T. Baker $^{3}$, R. Bhogal ${ }^{3}$ and F. Ahmed ${ }^{4,5}$
}

\begin{abstract}
Background: Chronic migraine (CM) is a neurological disorder associated with substantial disability. Botulinum toxin type A (Botox) is an approved and effective preventive treatment option for adult patients with CM. Transcranial magnetic stimulation (TMS) is an alternative treatment device delivering a brief pre-set magnetic pulse used for self-administration by the patient at home. Despite being available in a risk share scheme TMS is perceived to be more costly in the UK. The objective of this study was to analyse the incremental costs of TMS compared to Botox in refractory CM patients both for a UK individual funding request setting as well as for an average UK specialist center setting.

Methods: Cost impact results were derived from a decision-tree model simulating treatment pathways over 1 year. Costs were applied from the most recently available UK data sources. Sensitivity analysis was performed for all variables.

Results: Based on published utilisation data $45.5 \%$ of CM patients would continuously receive Botox over 1 year, whereas $53.7 \%$ of TMS patients would be still on treatment at the end of year one. Total costs of Botox treatment accrue to $£ 2923$ in an individual funding request NHS cost setting, whereas TMS treatment results in $£ 1466$ in the first year. Applying a time-based NHS cost setting expenditures accrue to $£ 1747$ for the Botox treatment and to $£ 1361$ for the TMS treatment. In both cost settings variation of cost assumptions did have a minor impact on the cost increment from Botox to TMS.

Conclusion: The current risk share based remuneration model of TMS allows the UK NHS to reimburse only the cost of those patients experiencing reduction in migraine days resulting in lower costs for treating migraine attacks. Treatment of chronic refractory migraine using TMS implies a substantial cost reduction potential for the management of chronic treatment of refractory migraine patients compared to conventional Botox treatment.
\end{abstract}

Keywords: Chronic migraine, Botox, TMS, Risk sharing, Economic analysis, Incremental costs, Pay for performance, Self-administration

\section{Background}

Chronic migraine $(\mathrm{CM})$ is a neurological disorder associated with substantial disability (Blumenfeld et al. 2011; Bigal et al. 2008; Harwood et al. 2004; Munakata et al. 2009; Natoli et al. 2010). CM is defined as experiencing headaches on at least 15 days per month for $\geq 3$ months, where $\geq 8$ of those days per month are with migraine

\footnotetext{
${ }^{*}$ Correspondence: bernd.brueggenjuergen@stw.de

${ }^{1}$ Institute for Health Economics, Steinbeis-University, Berlin, Germany Full list of author information is available at the end of the article
}

(Headache Classification Committee of the International Headache 2013). Refractory CM is a long-term disease, affecting around 610,000 people alone in the UK (Natoli et al. 2010; Ahmed 2011). Patients with CM are impacted by lower health-related quality of life and are more likely to suffer from severe disability (Blumenfeld et al. 2011; Harwood et al. 2004; Munakata et al. 2009; Lipton and Bigal 2003). This resulted in a low number of migraine prophylaxis trials as $\mathrm{CM}$ patients being considered to be too highly disabled and treatment resistant (Dodick et al. 2010). 
Costs are related both to acute drug treatment as well as to prophylaxis and discontinuation is a relevant factor for the latter. CM patients consume more direct healthcare resources than those with episodic migraine, such as acute medication use, physician visits and hospitalisations, along with a significant reduction in workplace productivity (Blumenfeld et al. 2011; Harwood et al. 2004; Munakata et al. 2009; Lipton and Chu 2009). Only few treatment options are available for refractory chronic migraine patients.

Botulinum toxin type A (Botox) is an approved and effective preventive treatment option for adult patients with chronic migraine (Aurora et al. 2011). Botox injections are administered intramuscularly by a trained physician to between 31 and 39 sites divided across 7 specific head and neck muscle areas every 12 weeks in a specialist outpatients hospital clinic setting. According to NICE guidelines eligible patients for Botox receive at least two consecutive cycles for treatment irrespective of whether they are responsive to treatment in the first cycle (NICE 2012).

Non-invasive neuromodulation devices are alternative treatment options in acute and preventive migraine therapy (Barbanti et al. 2015; Barker et al. 1985; Bhola et al. 2015). Spring $\mathrm{TMS}^{\mathrm{TM}}$ uses portable, single pulse transcranial magnetic stimulation technology. It is an approved and effective patient use device for both acute and preventive treatment of migraine. TMS technology was invented in the UK by the Royal Hallamshire NHS Hospital and University of Sheffield demonstrating the first stimulator in 1985 (Barker et al. 1985). In results from a UK Post Market Pilot programme Spring TMS demonstrated safety, efficacy and very good tolerability in acute migraine for daily and preventative treatment use (Bhola et al. 2015). The Spring TMS $^{\mathrm{TM}}$ device is placed against the back of the head for less than a second to deliver a very brief pre-set magnetic pulse. The magnetic field passes through the skull and tissue non-invasively and without discomfort to induce electrical currents along the cortex of the brain. Spring $\mathrm{TMS}^{\mathrm{TM}}$ is designed to be used for self-administration by the patient at home and requires minimal patient training.

The National Institute for Clinical Excellence (NICE) has approved TMS for clinical use through its Interventional Procedure Guidance (IPG) 477 January 2014. However, NICE has not yet completed a technology (cost) appraisal or issued a Technology Appraisal Guidance (TAG). TMS is available under a risk sharing programme in the UK, where the initial quarterly usage evaluates patient response to treatment. This first quarter is financed by the supplier. The subsequent quarter usage is to be paid by the NHS only for those patients benefiting from TMS observed as a reduction in migraine day frequency and or severity.

TMS addresses current NHS strategy to deliver services close to the patient and out of the hospital. The use of TMS supports Kings Fund first priority of self-management for commissioners to deliver a more efficient and effective system with improved outcomes for the patient including pain management.

However, the general perception about TMS among healthcare professionals and funding authorities is that the treatment is more expensive than existing therapies such as Botox and as a consequence many primary care physicians and migraine clinics have been reluctant to prescribe the device and have taken an Individual Funding Request route for TMS in exceptional cases. Hence, the objective of this cost analysis was to evaluate the incremental cost impact of TMS by comparing two real life treatment costs scenarios of Botox and TMS over 1 year both from an individual funding request perspective as well as from an average time-derived bottom-up UK cost center setting.

\section{Methods}

Our analysis outlines direct costs that accrue over time in patients with chronic refractory headache using either the pharmacologic injections or the risk sharing device-based preventive TMS treatment. The present study employs a cost analytic approach (Drummond et al. 2005). A decision analytic model was developed to outline the incremental cost impact of the risk-sharing approach of TMS compared to the traditional costing approach of Botox based on two alternative UK NHS costing settings. Modeling was performed using Treeage 2015.

\section{Model design}

The model assumes that after being considered eligible patients are treated consecutively over 5 cycles of Botox or four quarter of TMS unless patients discontinue treatment (Fig. 1). Botox patients are assumed to be treated at least over 2 consecutive 12 week-cycles according to the currently applied treatment scheme in the UK. TMS patients are subject for discontinuation after the initial quarter. It is assumed that those patients continuing either on Botox or TMS will remain on treatment until the end of the year.

\section{Outcome and treatment attrition}

For both treatment alternatives a reduction in resource utilisation when experiencing headache days for those patients responding of $49 \%$ for Botox and $47 \%$ for TMS were assumed (Bhola et al. 2015; Rothrock 2011). 


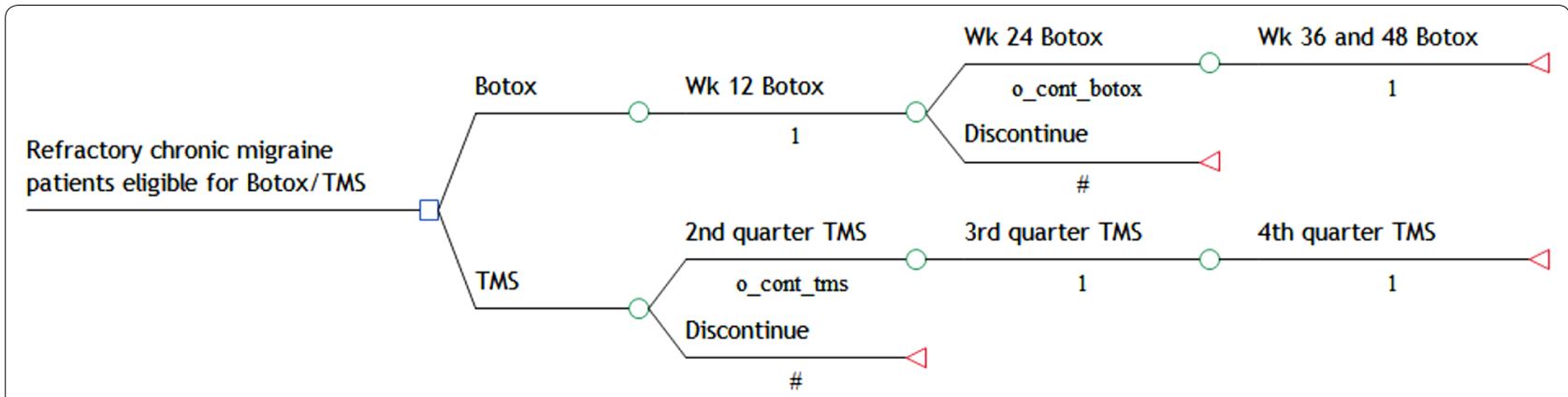

Fig. 1 Decision tree model for two alternative prophylactic treatment approaches in refractory chronic migraine patients in the UK

Responder rates were assumed to be identical with continuation rates. Values were based on published UK trial data resulting in $45.5 \%$ for Botox (Khalil 2015a) and $53.7 \%$ for TMS (Bhola et al. 2015).

\section{Costs}

In order to reflect potential NHS cost perspectives a bottom-up costing both for a scenario based on an individual funding authorisation perspective as well as an average time-based NHS resource use were calculated: Specialist center published fees of $£ 650$ per cycle for administering treatment, drug costs and follow-up visits and $£ 140$ for initial neurologist consultation were applied for the individual funding authorisation (Hull Royal Infirmary $\mathrm{K}-\mathrm{U}-\mathrm{H}$ 2012). For the time-derived cost setting the values were based on expert advice and NICE Botox appraisal values (NICE 2011). Hence, Botox resource consumption in the initial cycle would require $30 \mathrm{~min}$ specialists time resulting in $£ 70.00$ with unit cost of $£ 2.33$ applied (NICE 2011; Curtis 2014). Administering TMS would require one follow-up $15 \mathrm{~min}$ visit in the first quarter resulting in $£ 35.00$ (Table 1). Treatment period prorated administration and drug or device costs for the CM preventive treatment with either Botox or TMS were calculated for a maximum of 5 cycles and four consecutive quarters, resp. 12-weeks Botox drug costs of $£ 276.40$ (NICE 2011) and quarterly TMS costs of $£ 450$ (eNeura, Manufacturer) were applied.

Treatment cost components were covering costs for physician visits due to migraine, cost of hospital visits due to migraine, cost of emergency room visits due to migraine and symptomatic treatment costs per day with headache. UK specific resource use consumptions for standard treatment of CM patients were obtained from the International Burden of Migraine Study (IBMS) (Bloudek et al. 2012). Resource unit valuation was based on 2013 NHS tariff information if not stated differently either from the 2013-2014 tariff information spreadsheet or based on the PSSRU (Curtis 2014; Department_of Health 2013) (Table 1).

\section{Sensitivity analyses}

Deterministic one-way sensitivity analyses were performed both for the individual funding request setting as well as for the time-derived NHS setting. Apart from one variable (where Botox drug costs in week 48 for the low value assumes a $50 \%$ share for the first 6 weeks only) all other parameter were varied at $10 \%$. Sensitivity analyses have been reported in an incremental tornado diagram highlighting the impact of the assumptions on the potential incremental cost difference of the two preventive treatment choices in both settings.

\section{Results}

Based on the outlined assumptions $45.5 \%$ of CM patients would continuously receive Botox over 1 year. $53.7 \%$ of TMS patients would be still on treatment at the end of year one and are responding. Total costs of the Botox treatment accrue to $£ 2923$, whereas TMS treatment results in $£ 1466$ in the first year. Applying the time-based cost setting expenditures accrue to $£ 1747$ for the Botox treatment and to $£ 1361$ for the TMS treatment.

\section{Sensitivity analyses}

Sensitivity analyses are reported from an incremental cost perspective. The base case increment from Botox to TMS is $-£ 1466$ for the individual funding request setting and $-£ 386$ for the time-based setting. When varying values at $10 \%$ in the individual funding request setting Botox drug costs were the most influential variable (Range $-£ 1386$ to $-£ 1547$ ) followed by the cost for treating TMS responder (range $-£ 1394$ to $-£ 1539$ ) (Fig. 2).

The incremental changes due to variation of values in the time-based setting are most influenced when varying the drug costs of Botox (range $-£ 467$ to $-£ 306$ ) followed 


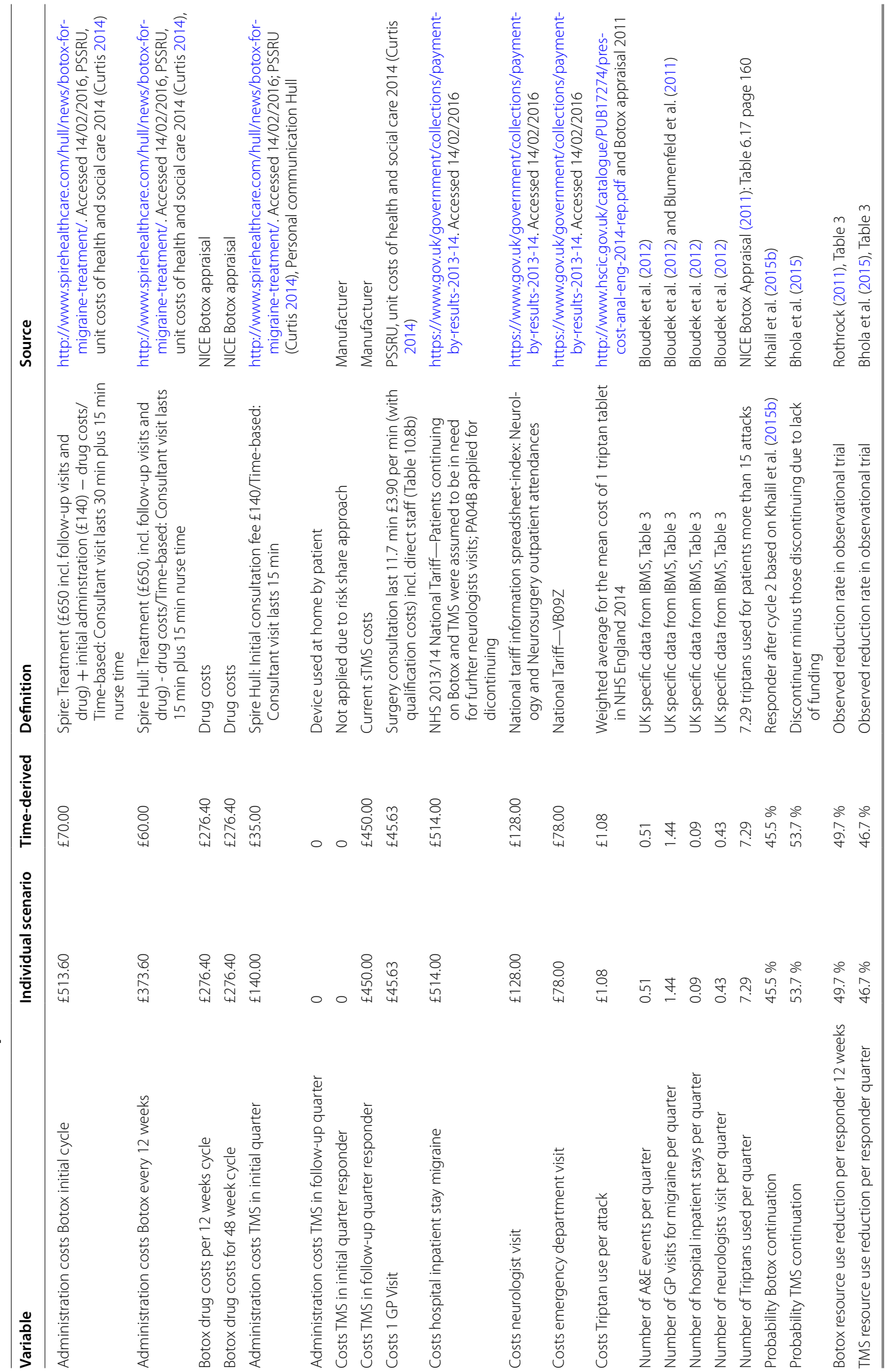




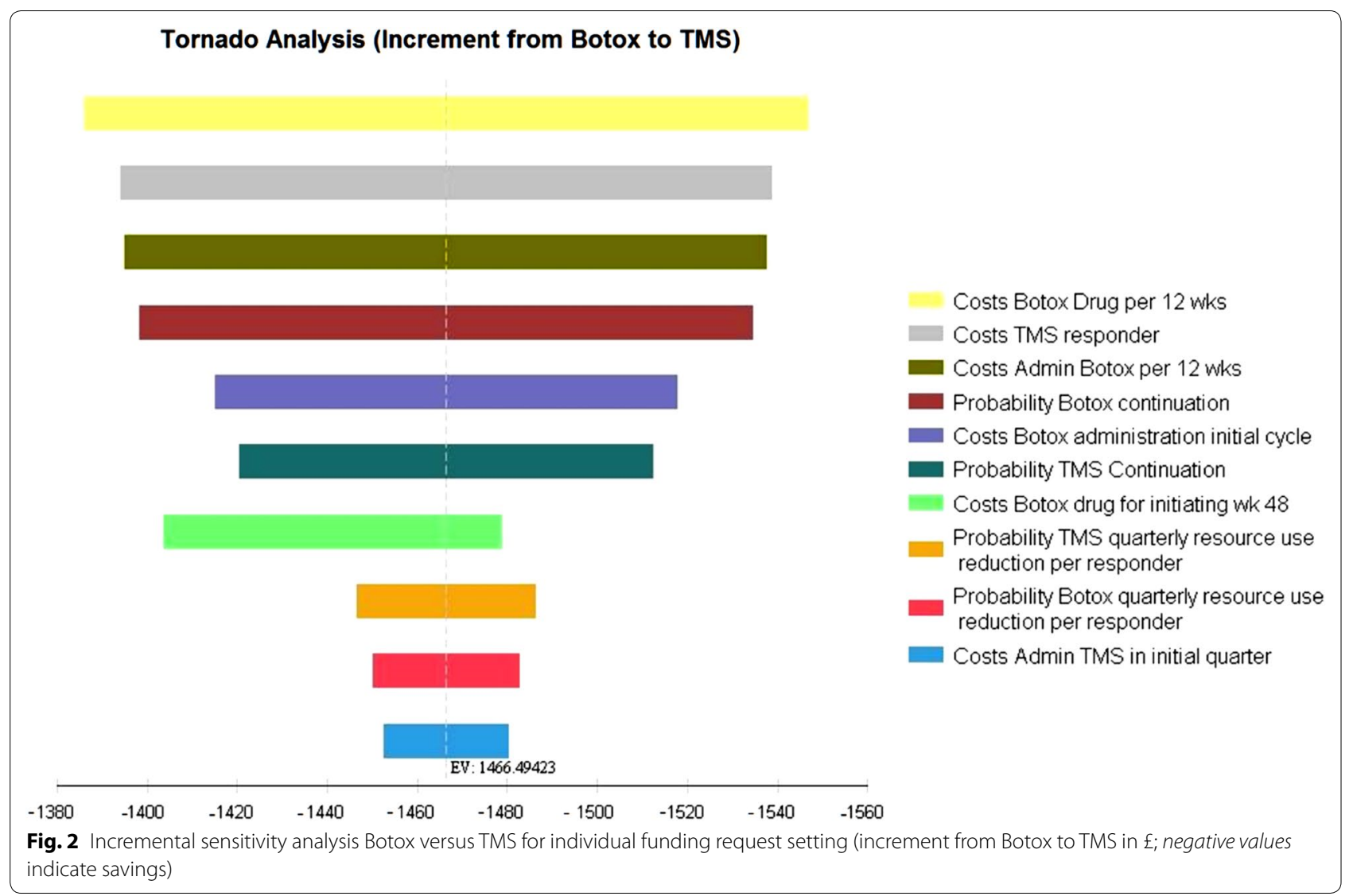

by the cost for TMS per quarter (range $-£ 459$ to $-£ 314$ ) (Fig. 3).

\section{Discussion}

This cost impact analysis compares 12-weekly Botox injections versus on demand patient applied TMS applications in refractory chronic migraine patients. Total annual cost of a chronic migraine patient in the UK accrue to $£ 3718$ and would result into a total UK cost burden of $£ 2.2$ billion when assuming a prevalence of $0.91 \%$ (Bloudek et al. 2012; Buse et al. 2012). From a NHS UK perspective, a potential for cost reduction of $£ 1466$ per patient in an individual funding request setting and $£ 386$ in a time-based average NHS cost setting was observed.

Our cost calculations are in the range of other cost analyses in chronic refractory patients conducted in other countries. The Scottish Medicines Consortium reports an incremental cost of $£ 1394$ when treating CM patients in addition with Botox (Scottish Medicines Consortium Submission 2011). A US analysis calculated annual cost related to Botox treatment of 4902 US \$, which is higher compared to both the individual funding request setting as well as the time-based average cost setting (Rothrock
2011). A German economic analysis of chronic cluster headache treatment assessed a comparable cost decrement of $€ 414$ for a non-invasive neuromodulatory technique in addition to standard of care (Morris et al. 2016).

Resource consumption data related to the treatment of chronic migraine patients in real life are sparse. Estimates of medical resource use were drawn from the International Burden of Migraine Study (IBMS) (Blumenfeld et al. 2011). Impact of assumptions on cost differences was tested with varying the underlying assumptions for all variables at $10 \%$, which resulted in only small deviations from the base case highlighting savings for TMS. Even when pro-rating the 48-week Botox drug costs, resulting in a bisection of the Botox drug cost in the fifth cycle, the increment from TMS to Botox remains negative at $£ 1404$. Hence, the size of the incremental differences is very robust to realistic changes of all parameters.

TMS is available under a pay for performance scheme in the UK, where the initial test quarter is free and the following quarters only have to be paid for responders. Risk sharing approaches in healthcare are not appropriate in all settings. Schemes should have realistic time scales and low administrative burden and should be based on sound evidence (Adamski et al. 2010). The TMS scheme is 


\section{Tornado Analysis (Increment from Botox to TMS)}

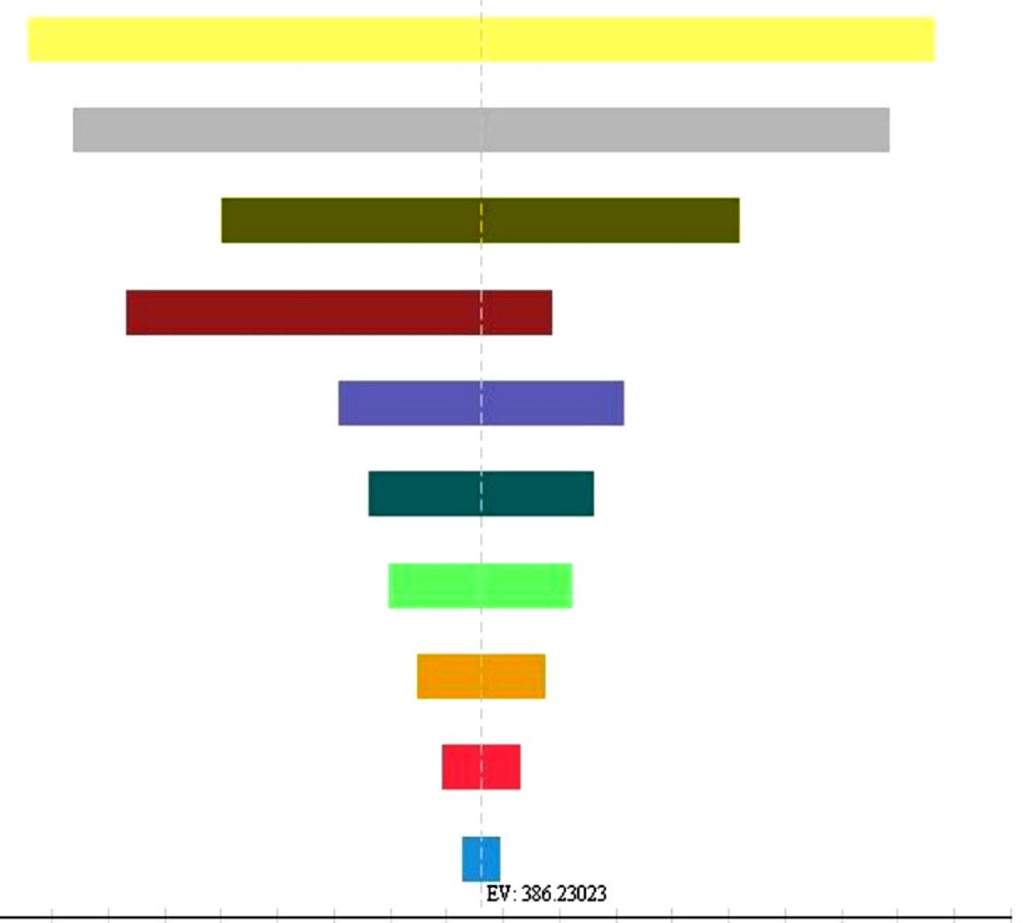

\section{Costs Botox Drug per 12 wks}

- Costs TMS in follow-up quarter responder

- Probability TMS Continuation

- Costs Botox drug for initiating wk 48

Probability Botox continuation

Probability TMS quarterly resource use reduction per responder

Probability Botox quarterly resource use reduction per responder

Costs Admin Botox per 12 wks

Costs Botox administration initial cycle

Costs Admin TMS in initial quarter

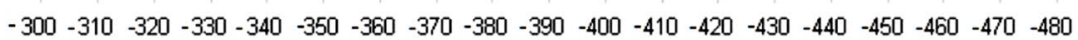

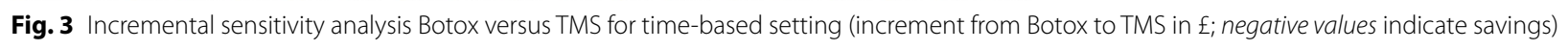

straightforward and places no further administrative burden on decision makers and hence is suitable for achieving cost reduction potentials in healthcare. However, there is presumably a low awareness of the risk sharing approach related to TMS, as still high cost perceptions anticipated for the non-drug treatment approach from a decision-maker point of view exist. Our analysis shows major cost reduction potentials for TMS user.

Our modelling might comprise some limitations: The current model does no account for potential differences in side effects, which are more pertinent with Botox being associated in a UK real-life setting with neck stiffness $(16 \%)$, injection site pain (15\%) and ptosis (9\%) (Khalil et al. 2015b). TMS patients reported minor neurologic symptoms only lasting up to $30 \mathrm{~min}$ after applying the first pulse (20\%) (Bhola et al. 2015). As with other cost analyses in CM patients our decision tree model only covers the initial year and hence those receiving a longer treatment period might not adequately be acknowledged.

A strength of our model is the focus on real life settings. Hence, with an individual specialist centre cost scenario and the most recent UK real life data selected our model in particular addresses the decision-maker's information needs of choosing efficient treatment options for severely impacted chronic migraine patients. Our cost assumptions are conservative as the expertise for the evaluation of eligible chronic migraine patients and for the individual treatment management decisions still remains scare in the UK and hence might result even in higher resource utilisation in those centres not being experienced with severe chronic migraine patients. In the Hull specialist centre the management of those 254 patients treated with Botox from 2010 to 2013 (Khalil et al. 2015b) would have resulted in a cost reduction of $£ 372,364$ (individual funding request assumptions) or $£ 98,044$ (time-based average NHS assumptions) if having been treated initially with TMS.

\section{Conclusion}

Both Botox and transcranial magnetic stimulation provide effective treatment approaches in patients with treatment-refractory chronic migraine in UK settings (Bhola et al. 2015; Khalil et al. 2014). TMS is perceived to induce higher costs compared to the pharmaceutical approach. Our decision analytic model demonstrates that treatment of chronic refractory migraine using TMS implies a substantial cost reduction potential for the management of treatment of chronic refractory migraine 
patients compared to conventional BOTOX treatment. The current risk share based remuneration model of TMS allows the National Health Service (NHS) to bear only the cost of those showing reduction in migraine days resulting in lower costs. Risk sharing is a relevant and future-oriented approach to performance based management in healthcare systems. Particularly in unclear efficacy situations risk sharing is providing an efficient approach for paymasters in healthcare and thus manages to balance patient needs and budgets when introducing innovative treatments.

\section{Authors' contributions}

BB drafted the manuscript and model. FA, TB and RB contributed to all section of the manuscript and reviews of the model. All authors read and approved the final manuscript

\section{Author details}

${ }^{1}$ Institute for Health Economics, Steinbeis-University, Berlin, Germany.

${ }^{2}$ Institute for Social Medicine, Epidemiology and Health Economics, Charité

University Medical Center, Berlin, Germany. ${ }^{3}$ eNeura Inc., Sunnyvale, CA, USA.

${ }^{4}$ Neurosciences Business Unit, Hull and Yorkshire Hospitals NHS Trust, Hull, UK.

${ }^{5}$ Hull York Medical School, Hull, UK.

\section{Acknowledgements}

We would like to thank Dr. Jörg Burkowitz and PD Dr. Thomas Reinhold for contribution in earlier preparational activities.

\section{Competing interests}

$\mathrm{BB}$ and FA declare no competing interests. TB and RB are employees of eNeura Inc., Sunnyvale, California, US.

\section{Funding}

eNeura Inc., Sunnyvale, California, US funded the analysis by a restricted grant.

Received: 13 June 2016 Accepted: 27 July 2016

Published online: 03 August 2016

\section{References}

Adamski J, Godman B, Ofierska-Sujkowska G, Osinska B, Herholz H, Wendykowska K et al (2010) Risk sharing arrangements for pharmaceuticals: potential considerations and recommendations for European payers. BMC Health Serv Res 10:153. doi:10.1186/1472-6963-10-153

Ahmed F (2011) Chronic migraine-diagnosing migraine. In: Diagnosing migraine. The Migraine Trust. https://www.migrainetrust.org/aboutmigraine/types-of-migraine/chronic-migraine/. Accessed 30 Jan 2015

Aurora SK, Winner P, Freeman MC, Spierings EL, Heiring JO, DeGryse RE et al (2011) OnabotulinumtoxinA for treatment of chronic migraine: pooled analyses of the 56-week PREEMPT clinical program. Headache 51(9):1358-1373. doi:10.1111/j.1526-4610.2011.01990.x

Barbanti P, Grazzi L, Egeo G, Padovan AM, Liebler E, Bussone G (2015) Noninvasive vagus nerve stimulation for acute treatment of high-frequency and chronic migraine: an open-label study. J Headache Pain 16:61. doi:10.1186/s10194-015-0542-4

Barker AT, Jalinous R, Freeston IL (1985) Non-invasive magnetic stimulation of human motor cortex. Lancet 1(8437):1106-1107

Bhola R, Kinsella E, Giffin N, Lipscombe S, Ahmed F, Weatherall M et al (2015) Single-pulse transcranial magnetic stimulation (sTMS) for the acute treatment of migraine: evaluation of outcome data for the UK post market pilot program. J Headache Pain 16:535. doi:10.1186/ s10194-015-0535-3

Bigal ME, Serrano D, Reed M, Lipton RB (2008) Chronic migraine in the population: burden, diagnosis, and satisfaction with treatment. Neurology 71(8):559-566 doi:10.1212/01.wnl.0000323925.29520.e7
Bloudek LM, Stokes M, Buse DC, Wilcox TK, Lipton RB, Goadsby PJ et al (2012) Cost of healthcare for patients with migraine in five European countries: results from the International Burden of Migraine Study (IBMS). J Headache Pain 13(5):361-378. doi:10.1007/s10194-012-0460-7

Blumenfeld AM, Varon SF, Wilcox TK, Buse DC, Kawata AK, Manack A et al (2011) Disability, HRQoL and resource use among chronic and episodic migraineurs: results from the International Burden of Migraine Study (IBMS). Cephalalgia 31(3):301-315. doi:10.1177/0333102410381145

Buse DC, Manack AN, Fanning KM, Serrano D, Reed ML, Turkel CC et al (2012) Chronic migraine prevalence, disability, and sociodemographic factors: results from the American Migraine Prevalence and Prevention Study. Headache 52(10):1456-1470. doi:10.1111/j.1526-4610.2012.02223.x

Curtis L (2014) Unit costs of health and social care 2014. The University of Kent, Canterbury

Department_of_Health (2013) Payment by Results 2013-14. In: Department_ of_Health (ed) https://www.gov.uk/government/collections/paymentby-results-2013-14. GOV.UK Department of Health.

Dodick DW, Turkel CC, DeGryse RE, Aurora SK, Silberstein SD, Lipton RB et al (2010) OnabotulinumtoxinA for treatment of chronic migraine: pooled results from the double-blind, randomized, placebo-controlled phases of the PREEMPT clinical program. Headache 50(6):921-936. doi:10.1111/j.1526-4610.2010.01678.x

Drummond MF, Sculpher M, Torrance G, O'Brien B, Stoddart GL (2005) Methods for the economic evaluation of health care programmes. Oxford University Press, Oxford

Harwood RH, Sayer AA, Hirschfeld M (2004) Current and future worldwide prevalence of dependency, its relationship to total population, and dependency ratios. Bull World Health Organ 82(4):251-258

Headache Classification Committee of the International Headache Society (2013) The international classification of headache disorders, 3rd edition (beta version). Cephalalgia 33(9):629-808. doi:10.1177/0333102413485658

Hull Royal Infirmary K-U-H, UK (2012) Chronic Migraine injection treatment available at Spire Hull and East Riding Hospital. Spire Hull and East Riding Hospital, Hull. http://www.spirehealthcare.com/hull/news/botox-formigraine-treatment/. Accessed 10 Feb 2016

Khalil M, Zafar HW, Quarshie V, Ahmed F (2014) Prospective analysis of the use of OnabotulinumtoxinA (BOTOX) in the treatment of chronic migraine; real-life data in 254 patients from Hull, UK. J Headache Pain. 15:54. doi:10.1186/1129-2377-15-54

Khalil M, Zafar H, Ahmed F (2015a) How long to continue Botox in chronic migraine patients? A two year follow up of 248 patients treated in Hull, UK. Annual Meeting of the International Headache Society, Valencia

Khalil M, Zafar H, Ahmed F (2015b) Hull prospective analysis of OnabotulinumtoxinA (Botox) ${ }^{\circledR}$ in the treatment of chronic migraine; real-life data in 465 patients; an update. International Headache Society $(\mathrm{IHC})$, Valencia

Lipton RB, Bigal ME (2003) Chronic daily headache: is analgesic overuse a cause or a consequence? Neurology 61(2):154-155

Lipton RB, Chu MK (2009) Conceptualizing the relationship between chronic migraine and episodic migraine. Expert Rev Neurother 9(10):1451-1454 doi:10.1002/pmic.200800454

Morris J, Straube A, Diener HC, Ahmed F, Silver N, Walker S et al (2016) Cost-effectiveness analysis of non-invasive vagus nerve stimulation for the treatment of chronic cluster headache. J Headache Pain 17:43. doi:10.1186/s10194-016-0633-x

Munakata J, Hazard E, Serrano D, Klingman D, Rupnow MF, Tierce J et al (2009) Economic burden of transformed migraine: results from the American Migraine Prevalence and Prevention (AMPP) Study. Headache 49(4):498508. doi:10.1111/j.1526-4610.2009.01369.x

Natoli JL, Manack A, Dean B, Butler Q, Turkel CC, Stovner L et al (2010) Global prevalence of chronic migraine: a systematic review. Cephalalgia 30(5):599-609. doi:10.1111/j.1468-2982.2009.01941.x

NICE (2011) Botulinum toxin type A for the prophylaxis of headaches in adults with chronic migraine. National Institute for Health and Clinical Excellence, London

NICE (2012) Botulinum toxin type A for the prevention of headaches in adults with chronic migraine. In: Excellence NIfHaC (ed) NICE technology appraisal guidance. NICE, London

Rothrock JF (2011) Onabotulinumtoxin A for the treatment of chronic migraine. Headache 51(4):659-660. doi:10.1111/j.1526-4610.2011.01880.x 